\title{
A DESCONSTRUÇÃO DO MITO DA DEMOCRACIA RACIAL E O RACISMO ESTRUTURAL NO BRASIL: EDUCAÇÃO E TRANSFORMAÇÃO SOCIAL
}

\author{
THE DECONSTRUCTION OF THE MYTH OF RACLAL \\ DEMOCRACY AND STRUCTURAL RACISM IN BRAZIL: \\ EDUCATION AND SOCLAL TRANSFORMATION
}

\author{
Danilo Henrique Nunes ${ }^{1}$ \\ Lucas Souza Lehfeld ${ }^{2}$ \\ Carlos Eduardo Montes Netto ${ }^{3}$
}

\section{Recebido em: 30/06/2021 Aceito em: 08/09/2020 \\ dhnunes@hotmail.com lehfeldrp@gmail.com carlosmontes3@hotmail.com}

Resumo: O mito da democracia racial consiste em uma teoria inconsistente a partir da qual era identificado que no Brasil e em certos países da América Latina, indivíduos marginalizados como indígenas e negros viviam em condição de plena igualdade com os brancos, em um contexto amplamente distinto da realidade estimulada pelo colonialismo e pelo racismo enraizado na sociedade brasileira. $O$ presente artigo científico busca desconstruir o mito da democracia racial no Brasil, apresentando o pensamento decolonial e reafirmando a educação e a economia como instrumentos voltados para a transformação social, enfrentando o racismo estruturado no país. Foi realizada uma pesquisa bibliográfica com emprego do método hipotético-dedutivo, analisando as contribuições de outros autores para fomentar uma conclusão verdadeiramente aplicável ao problema exposto. Os resultados alcançados com o desenvolvimento da pesquisa contribuíram para o entendimento da democracia racial como uma mera ficção ideológica, sendo o movimento decolonial imprescindível para a concretização de uma transformação de combate ao racismo, na mesma medida que a ressignificação do papel e da identidade do negro e das demais minorias inviabilizadas desempenha a função de transformação no âmbito da educação e da economia na contemporaneidade.

Palavras-chave: Democracia Racial; Pensamento Decolonial; Racismo no Brasil; Educação.

Abstract: The myth of racial democracy consists of an inconsistent theory from which it was identified that in Brazil and in certain Latin American countries, marginalized individuals such as indigenous and black people lived in a condition of full equality with whites, in a context that is widely different from reality stimulated by colonialism and racism rooted in Brazilian society. This scientific article seeks to deconstruct the myth of racial democracy in Brazil, presenting decolonial thinking and reaffirming education and economics as instruments aimed at social transformation, facing structured racism in the country. A bibliographic search was carried out using the hypothetical-deductive method, analyzing the contributions of other authors to foster a conclusion that is truly applicable to the problem exposed. The results achieved with the development of the research contributed to the understanding of racial democracy as a mere ideological fiction, with the decolonial movement being essential for the realization of a transformation to combat racism, in the same measure as the redefinition of the role and identity of black people. and of the other unviable minorities, it plays the role of transformation in the field of education and economics in contemporary times.

Keywords: Racial Democracy; Decolonial Thinking; Racism in Brazil; Education.

\footnotetext{
${ }^{1}$ Universidade de Ribeirão Preto - Unaerp. Ribeiro Preto. São Paulo. Brasil.

${ }^{2}$ Universidade de Ribeirão Preto - Unaerp. Ribeiro Preto. São Paulo. Brasil.

${ }^{3}$ Universidade de Ribeirão Preto - Unaerp. Ribeiro Preto. São Paulo. Brasil.
} 


\section{INTRODUÇÃO}

Desde o período de colonização do Brasil o país enfrenta um racismo enraizado e associado à uma percepção imposta pelo homem branco como dominador dos demais povos, como os negros e indígenas, tidos como seres inferiores em relação aos caucasianos (FERNANDES: 1978). A história brasileira, nesse sentido, é em grande parte uma história que se confunde com a própria história do racismo, mesmo com tentativas de mascarar ou amenizar o problema e as lutas raciais no país, como ocorre com a questão da democracia racial. De acordo com Andrews (1997) a democracia racial pode ser definida como uma suposta situação de igualdade entre brancos, negros e multados no Brasil na primeira metade do século $X X$, associada à visão de observadores nativos e estrangeiros sobre o país e que persistiu por boa parte da história. Tal mito, entretanto, passou a ser desconstruído diante dos relatos de situações de disparidades entre as populações brancas e populações não-brancas no tocante à educação, ao trabalho, à vida financeira e à experiência social.

Isso posto, o objetivo geral do presente estudo consiste em desconstruir o mito da democracia racial, ao mesmo tempo em que é analisado o pensamento decolonial e o papel desempenhado pela educação e pela economia no âmbito de uma transformação social que possa realmente proporcionar o enfrentamento das desigualdades raciais. Para tanto, foram definidos os seguintes objetivos específicos: a) proporcionar uma análise crítica sobre a democracia racial e sobre o racismo enraizado no Brasil; b) contemplar o racismo estrutural na contemporaneidade, versando sobre aspectos como gênero, raça e o pensamento decolonial; c) verificar no que consistem os espaços de fala, contemplando políticas públicas e ações afirmativas, além da indispensabilidade dos diálogos com a sociedade civil; e, d) apresentar possibilidades de transformação social a partir de aspectos relacionados à educação e à economia.

A elaboração do presente estudo parte da realização de uma pesquisa bibliográfica com aporte do método hipotético-dedutivo, o qual, de acordo com Prodanov e Freitas (2013) consiste em um método que envolve a definição de um problema ou lacuna no conhecimento científico, passando pela formulação de hipóteses e pela interferência dedutiva. $O$ emprego deste método juntamente com a revisão de literatura permite uma análise concisa dos fenômenos que aqui serão analisados, conduzindo o estudo para uma conclusão verdadeiramente aplicável sobre o fenômeno da democracia racial e suas implicações.

\section{DEMOCRACIA RACIAL E CONTEXTO HISTÓRICO: FUNDAMENTO DO RACISMO BRASILEIRO}

Aqui o estudo consiste em uma abordagem envolvendo conceitos relacionados à democracia racial e perspectivas que envolvem o racismo enraizado no Brasil, a partir de uma perspectiva histórica. 


\subsection{Noções de Democracia Racial}

Segundo Guimarães (2019) as primeiras noções de democracia racial foram divulgadas como um modo de convivência racial próprio do Brasil e da América Latina, servindo como uma espécie de antídoto para o racismo perpetuado pelos norte-americanos, marcados pela segregação e linchamentos, justificando a precariedade democrática da América Latina e sendo apresentada ironicamente como uma solução aos intelectuais negros dos Estados Unidos na luta pela igualdade racial, política e econômica, os quais já conheciam essa expressão pelo menos desde 1914. Ao analisar a democracia racial brasileira no período 1900-1990, Andrews (1997) aponta que seu conceito está associado à visão de observadores nativos e estrangeiros sobre o Brasil na primeira metade do século XX, envolvendo uma suposta democracia na qual indivíduos negros, mulatos e brancos viviam sob condições de igualdade jurídica e, em grande parte, social. Contudo, tal descrição passou a ser revisada a partir da década de 1940, quando passaram a ser relatadas as disparidades presentes entre a população branca e as populações não-brancas em relação à educação, trabalho, vida financeira e experiência social. A suposta harmonia em condições de igualdade no país, para o autor, é uma visão distorcida da realidade racial contemplada no país.

Ribeiro (2018) aponta que a democracia racial foi uma forma de negação da existência do racismo (ou, nas palavras utilizadas pela autora, um racismo à brasileira), sendo necessário romper com esse mito e com os reflexos dele para promover uma análise congruente com as perspectivas que envolvem o racismo no país. Tal entendimento é amplamente promovido na literatura sobre a democracia racial, envolvendo tanto autores que representam os movimentos e coletivos negros, como pesquisadores das questões raciais do Brasil como um todo.

Ao longo das décadas de 1960 e 1970 a democracia racial funcionou como uma espécie de mecanismo para mascarar as desigualdades raciais brasileiras e o racismo institucional e estrutural, embora possa ser apontada como eficaz para inibir manifestações mais grosseiras do racismo, com um uso doméstico do Brasil que passou a se disseminar por toda a América Latina, sobretudo em países de formações raciais negras relevantes, como Cuba, Colômbia e Venezuela, quando os protestos negros passaram a ganhar notoriedade na cena política do continente, revertendo a invisibilidade criada pelo imaginário de nações mestiças (GUIMARÃES: 2019). De acordo com Silva e Skolaude (2020, p. 334) a democracia racial "foi instituída, a partir dos anos de 1930, como um dispositivo de segurança, o que nos conduz a pensar a educação antirracista como uma contranarrativa à biopolítica que constituiu um regime de verdades sobre a nação", negando os efeitos da desigualdade entre diferentes etnias e maquiando o racismo amplamente praticado sobretudo com relação às pessoas que constituem as populações negras. Nesse sentido:

O racismo no Brasil é uma experiência gravíssima que perpassa todas as nossas relações sociais. Podemos constatá-lo através do genocídio da juventude negra, do encarceramento seletivo, dos índices de interrupção da trajetória escolar de crianças e jovens negros, do sofrimento de mães e mulheres nos espaços de saúde e casas de parto, da gritante diferença salarial, da baixa representatividade em espaços de tomada de decisão, produção e difusão do saber, bem como dos índices de violência 
doméstica e sexual que demonstram que a maioria das vítimas são mulheres negras. Estas e tantas outras não citadas situações evidenciam a desigualdade racial que perpassa nossas relações cotidianas, essas experiências têm sido cada vez mais estudadas e discutidas nos meios acadêmicos (VIDAL: 2019, p. 6).

Ora, a denúncia do "mito" da democracia racial se dá em uma mera observação da prática: o país sempre contou com um racismo estruturado ao longo da história, mesmo com uma população composta em grande parte por indivíduos negros. Corroboro com o entendimento de que a suposta democracia racial do século XX nada mais serviu do que como uma "cortina de fumaça" para os reais problemas e desigualdades do país, ainda que possa ter contribuído para a diminuição de atos racistas mais grosseiros. Mais adiante, serão aprofundadas outras questões que envolvem a democracia racial como um todo, retomando esse ponto. Doravante, será apresentado um tópico que contempla o embasamento teórico acerca do racismo como uma prática enraizada no Brasil.

\subsection{Do Racismo enraizado no caso Brasileiro}

Em sua obra "O que é racismo estrutural?" Almeida (2018) conceitua o racismo como "uma forma sistemática de discriminação que tem a raça como fundamento, e que se manifesta por meio de práticas conscientes ou inconscientes que culminam em desvantagens ou privilégios para indivíduos, a depender do grupo racial ao qual pertençam", sendo costumeiramente tratado como sinônimo de preconceito racial de discriminação racial, uma vez que: o preconceito racial consiste no juízo que se baseia em estereótipos evolvendo indivíduos que pertencem a um determinado grupo racializado, podendo resultar ou não em práticas discriminatórias. Exemplos de preconceito racial citados pelo autor consistem em uma pessoa que considera os negros como violentos e inconfiáveis, os judeus como avarentos ou os asiáticos como "naturalmente" bons em ciências exatas; e, ainda, já a discriminação racial consiste na atribuição de tratamento diferenciado a membros de um grupo racialmente identificado, tendo como requisito fundamental o poder para atribuir vantagens e desvantagens em função da raça.

Segundo Fernandes (1978) as pessoas caucasianas se apropriaram e instituíram o racismo no país desde a chegada do homem branco no Brasil, dominando as populações nativas das terras tupiniquins. O racismo brasileiro, para tal autor, está associado à uma percepção de indivíduos como negros e indígenas como inferiorizados em relação aos brancos, estes tendo a si próprios como superiores e dominadores dos demais povos. O autor abrange, inclusive, a democracia racial, afirmando que a mesma consiste em nada mais do que uma ficção ideológica em um país que contou com o racismo ao longo de toda a sua história civilizada. Para Pontes e Silva e Florencio (2018) o caso brasileiro representa uma negação constante do racismo enraizado como um problema que acompanhou o país ao longo de toda a sua história e que persiste na atualidade. A criança negra, por exemplo, tem sua voz silenciada e passa a sentir na pele o que é o racismo desde a mais tenra idade, inclusive na escola, mesmo sem entender exatamente por qual motivo sofre aquilo. A mera cor da pele e a ancestralidade desses povos foi o suficiente para que o homem branco se impusesse como o "ser superior" e "conquistador". Assim: 
(...) a despeito dos avanços alcançados em relação ao reconhecimento e à efetivação do acesso a direitos fundamentais pelos negros no Brasil, sobretudo a partir do advento da $\mathrm{CF} / 88$ (que elevou o racismo à categoria de crime e garantiu a igualdade racial, ao menos do ponto de vista formal) e da implementação de políticas públicas de discriminação positiva, que se seguiram à promulgação do Estatuto da Igualdade Racial (consubstanciadas nos sistemas de cotas para ingresso em universidades e cargos públicos federais), estamos ainda distantes de podermos afirmar e comemorar a concretização da democracia racial consagrada pelo texto constitucional (BARBOSA LIMA: 2020, p. 130).

A autora supramencionada leciona que o racismo enraizado na sociedade brasileira possuí claramente raízes históricas, estabelecendo um sistema de opressão social em desfavor dos marginalizados. E o racismo não é reproduzido tão somente nos discursos, mas também em atos de violência contra a população negra e de exclusão e segregação dessa população, como no caso das favelas brasileiras, localizações pobres no Brasil constituídas por uma maioria de negros e pardos. Enquanto houver tal racismo enraizado na sociedade brasileira, não há como se falar de modo algum em uma democracia racial e, quando se falou nela anteriormente, não passou de um autoengano ou de um esforço motivado para apagar ou disfarçar o racismo estrutural amplamente presente no Brasil. O racismo, outrossim, acaba afetando de modo significativo a vida de tais pessoas marginalizadas: ao longo de sua vida, uma pessoa negra pode se deparar com diversas situações onde o racismo se faz presente, seja na escola, no mercado de trabalho ou em qualquer outro contexto social. Ao sofrer com o racismo, o indivíduo tem menosprezada a sua identidade e é colocado em uma posição de inferioridade em relação às pessoas brancas.

\section{RACISMO ESTRUTURAL CONTEMPORÂNEO: DESCONSTRUÇÃO DA DEMOCRACIA RACIAL}

Conforme observado acima, o racismo é uma questão histórico enfrentado pelo Brasil e muitas vezes ignorado ou silenciado, a exemplo de uma suposta "democracia racial" que nunca se confirmou na prática, seja por autoengano ou por esforços coordenados para disfarçar a existência do preconceito e das desigualdades que afligem as pessoas negras e as pessoas marginalizadas como um todo, como no caso dos indígenas. Contudo, também ficou demonstrado como esse racismo enraizado acompanhou a sociedade brasileira até os tempos atuais, questão que será aprofundada a seguir.

\subsection{Gênero, raça e pensamento decolonial}

Segundo Novais Reis e Andrade (2018) o colonialismo europeu foi um fenômeno que gerou complexas marcas na civilização dos povos colonizados, de modo que o pensamento decolonial funciona visando a problematização acerca das condições colonizadas da epistemologia, buscando a emancipação de todos os tipos de dominação e opressão oriundos das imposições coloniais. Como visto anteriormente o processo de colonização resultou na exploração dos nativos do Brasil, sendo 
possível citar outras perspectivas que envolvem as nocividades do colonialismo, como no transporte marítimo de escravos para que os mesmos trabalhassem no Brasil e em outros países da América do Sul. Para exemplificar no que consiste o pensamento decolonial é possível citar o exemplo da educação ilustrado pelos ensinamentos de Nascimento e Pirra (2018): ao chegarem nas terras tupiniquins, os colonizadores portugueses passaram a impor seus costumes, sua linguagem e até mesmo seu modo de educar, com o apoio dos jesuítas para imposição também da religião. Nesse sentido, o pensamento decolonial representa uma prática social de descolonização da educação, a tornando mais humanizadora ao promover a conscientização de sujeitos que foram silenciados e marginalizados pelo eurocentrismo e pela colonização, visando a emancipação de saberes e identidades. Assim, o colonialismo:

operou a inferiorização de grupos humanos não-europeus, do ponto de vista da produção da divisão racial do trabalho, do salário, da produção cultural e dos conhecimentos. (...) fala também da colonialidade do saber, entendida como a repressão de outras formas de produção de conhecimento nãoeuropeias, que nega o legado intelectual e histórico de povos indígenas e africanos, reduzindo-os, por sua vez, à categoria de primitivos e irracionais, pois pertencem a "outra raça" (OLIVEIRA; CANDAU: 2010, p. 20).

Ribeiro (2018) aponta que a descolonização do conhecimento passa pela identidade social, com o intuito não apenas de demonstrar como o projeto de colonização criou identidades, mas também para comprovar como determinadas identidades foram (e têm sido) historicamente silenciadas e desautorizadas no sentido epistêmico, enquanto outras identidades são fortalecidas. Essa perspectiva é válida, por exemplo, para as questões de raça, onde a colonização silenciou as identidades dos indígenas e dos escravos para fortalecera identidade do homem branco europeu; no mesmo sentido, é possível trazer tal discussão para o campo do gênero/sexo, onde o pensamento colonial influenciou novamente no fortalecimento da identidade do homem branco europeu, desprivilegiado e desmerecendo as identidades de mulheres e homossexuais.

Em obra intitulada "Novas Perspectivas para a Antropologia Jurídica na América Latina: o Direito e o Pensamento Decolonial" Colaço e Damázio (2012, p. 8) afirmam que o "pensamento decolonial reflete sobre a colonização como um grande evento prolongado e de muitas rupturas e não como uma etapa histórica já superada". Assim, não são menosprezados os efeitos e impactos a longo prazo pela influência e pelas imposições dos colonizadores no Brasil e em outros países que serviram como colônias europeias ao redor do globo, reconhecendo que o processo de colonização acabou fornecendo uma herança histórica e amplamente percebida no silenciamento de identidades:

A decolonialidade surge naturalmente a partir dos sujeitos dominados e racializados como inferiores que, a partir dos seus saberes "locais", buscam expor a lógica de subalternização da modernidade/colonialidade (...) Por exemplo, o termo "pensamento decolonial" se entende no universo de expressões semelhantes tais como "pensamento econômico", "pensamento científico", "pensamento linear". Cada adjetivo nomeia uma esfera ou um universo de sentido que caracteriza um pensar particular (COLAÇO; DAMÁZIO: 2012, p. 143). 
Bouteldja (2016) defende que a perspectiva decolonial pode definir um sujeito revolucionário, a partir do qual é construído um projeto de transformação social que reflete e pondera sobre os efeitos da colonização envolvendo conceitos como a raça, classe e gênero, dando origem ao que a autora denomina como uma nova divindade de três cabeças. Oliveira e Candau (2010) discutem no mesmo sentido que o pensamento decolonial consiste em analisar a colonialidade como constitutiva (e não como derivada) da modernidade, compreendendo que a modernidade e a colonialidade seriam duas faces de uma mesma moeda: o colonialismo atingiu as mais profundas raízes dos povos colonizados, sobrevivendo ao longo do tempo mesmo com a emancipação de colônias na América Latina, Ásia e África ao longo dos séculos XIX e XX.

Essa mesma perspectiva é reafirmada por Novais Reis e Andrade (2018, p. 4) ao contemplarem que "As marcas indeléveis da situação colonial simplesmente não abandonaram os povos colonizados, tampouco os abandonarão, tendo-se em vista a magnitude da operação do processo colonial que hodiernamente se desdobra na colonialidade do poder". A percepção atual sobre questões relacionadas à raça e ao gênero, outrossim, estão intimamente relacionadas ao processo de colonização do Brasil, de modo que o pensamento decolonial busca refletir sobre tal relação com o intuito de promover mudanças e transformação social. De acordo com Ballestrin (2013) o racismo é um traço próprio do colonialismo e se estabelece a partir de pequenas diferenças entre os povos, em oposição à diversidade. Um povo domina o outro e impõe seus costumes, sua religião, suas vestimentas, seu idioma. E, não obstante, também coloca a si próprio como um povo superior, destinado ao domínio dos seus inferiores. E o pensamento decolonial busca justamente fornecer um contraponto em relação às influências coloniais, as combatendo na medida em que pensa criticamente sobre o processo de colonização e as marcas deixadas por ele.

Nesse ponto, é possível aproximar o pensamento decolonial da democracia racial, uma vez que a suposta democracia racial defendida em outros tempos maquiava as influências históricas do homem branco sobre o homem negro e o indígena no Brasil. Reafirmar a democracia racial como um mito e a descontruir é um caminho voltado para o pensamento decolonial, na mesma medida em que o pensamento e o movimento decolonial podem contribuir para que haja, de fato, uma democracia racial em um momento futuro.

\subsection{Desconstrução do racismo por uma perspectiva decolonial}

Quadros (2019, p. 39) defende que segundo o pensamento decolonial "o conceito de raça é fundamental para entender a estrutura hierárquica de poder, do qual a ordem vigente do sistema internacional é formada", sendo que a ideia de "raça" foi estruturada para outorgar uma suposta legitimidade para a imposição da conquista colonial, formando um discurso amparado na relação do colonizador versus o colonizado. Nesse cenário, as raças inferiorizadas devem contemplar uma perspectiva decolonial tanto para a desconstrução quanto para o combate ao racismo. Westrup e Barabas (2019) lecionam que o pensamento decolonial demonstra que a atualidade apresenta a colonialidade como uma nova forma de poder mundial baseada em marcadores de opressão, como 
raça, gênero e classe, os quais serviram como instrumentos de dominação dos povos colonizados em relação ao eurocentrismo. De acordo com os autores, boa parte das teorias raciais do passado se estruturaram na sociedade ao negar o racismo a partir do mito da democracia racial, o qual continua a delimitar os espaços destinados à resistência, sobretudo envolvendo o povo negro:

O racismo é um fator estruturante construtor de subjetividades na sociedade brasileira, assinalada pela ideia da superioridade das pessoas brancas em relação às pessoas negras, principalmente pela construção e difusão do mito da democracia racial. No Brasil a lógica do sistema escravocrata ainda não ultrapassada, sendo o último país na América a "abolir" a escravidão; uma abolição meramente formal, que não se concretizou materialmente, tendo em vista que a população negra colocada à margem, excluída e estigmatizada nas mais diversas esferas sociais, dificultando assim o direito à cidadania. A prática do racismo é dissimulada e se desconstruída pela negação da sua existência, fundamentado no mito da democracia racial, onde negros e brancos possuem igualdade de direitos, numa concepção da ausência de conflitos raciais (WESTRUP; BARABAS: 2019, pp. 2-3).

Ainda de acordo com os autores supramencionados, o racismo se aproxima de uma patologia, sendo uma violência cometida por um indivíduo com fundamento no ódio à cor da pele diferente da sua e, em grande parte, a herança histórica do colonialismo. Por muitas vezes o racista sente "orgulho" de ser acometido com essa patologia, em um delírio a partir do qual o mesmo se vê como um ser superior (um colonizador) que deve dominar o ser inferior (o colonizado), mesmo século após o desmantelamento do Brasil Colônia. Evidentemente, com a evolução da sociedade e do Direito foram realizadas importantes inovações que contribuíram para aumentar a igualdade de direitos entre, por exemplo, indivíduos negros e brancos, mas tais avanços apenas configuram uma igualdade étnica formal, posto que, na prática, o racismo continua sendo uma prática constante e institucionalizada.

Políticas públicas e ações afirmativas, especialmente as de educação, nesse sentido, não foram realmente eficientes e eficazes na luta contra o racismo, como veremos mais adiante, ainda que possam ser compreendidas como avanços relevantes para a desconstrução das questões de raça. O que se busca defender aqui é que, além da desconstrução do mito da democracia racial, a desconstrução do racismo passa pelo pensamento e pelo movimento decolonial, refletindo criticamente sobre as raízes históricas do racismo estrutural instaurado no Brasil.

\section{ESPAÇOS DE FALA: PAUTA E PRÁTICAS ANTIRRACISTAS}

Promover a igualdade de direitos entre diferentes povos, embora seja uma etapa fundamental de transformação social, é ação ineficiente para promover uma real desconstrução do racismo. O presente capítulo se distingue em dois subcapítulos distintos: no primeiro, será realizada uma análise crítica sobre as ações afirmativas e políticas públicas; no segundo, será dado enfoque para os diálogos com a sociedade civil. 


\title{
4.1 Políticas Públicas e Ações Afirmativas (in)efetivas
}

Ribeiro (2018) aponta que após os quase quatro séculos de escravidão no Brasil, onde a população negra trabalhou exclusivamente para o enriquecimento e para o atendimento das vontades dos brancos, foi incentivada a vinda de imigrantes europeus para o país, Ihes oferecendo acesso a trabalho remunerado e terras, em uma ajuda inicial do governo que oferece na atualidade uma realidade confortável. Contudo, a autora aponta que para a população negra não foram criados mecanismos de inclusão: o negro foi tirado da senzala e mandado para a favela, o que certamente consistiu em uma herança escravocrata que acompanhou e continuará acompanhando as futuras gerações negras. A autora supramencionada versa sobre as ações afirmativas, as contemplando como ações justas e necessárias em uma sociedade excludente e injusta com a população negra, com o intuito de diminuir a distância e as desigualdades:

\begin{abstract}
Aos que se mostram contrários às cotas, indico que pesquisem sobre o conceito de equidade aristotélica: as ações afirmativas também se baseiam nele, que basicamente implica tratar desigualmente os desiguais para promover a efetiva igualdade. Ou seja, se duas pessoas vivem em situações desiguais, não se pode aplicar o conceito de igualdade abstrata, porque concretamente é a desigualdade que se verifica. Aquela pessoa que está em situação de desigualdade precisa de mecanismos que visem a seu acesso à cidadania (RIBEIRO: 2017, p. 49).
\end{abstract}

Hofbauer (2006, p. 10) traz um contraponto em relação às ações afirmativas e políticas públicas voltadas para povos racializados, uma vez que a "proposta de introduzir ações afirmativas como meio para contrabalançar os efeitos históricos de discriminações estruturais, não consegue, porém, gerar consenso nem mesmo entre estudiosos do assunto": de um lado, há os que entendem a introdução de ações afirmativas como uma precondição para a superação das discriminações, com uma discriminação positiva que irá acolher aqueles historicamente desprivilegiados, contribuindo para a criação e o fortalecimento de uma identidade positiva; outros, veem as próprias ações como um perigo para a relação entre as diferenças humanas, podendo instigar conflitos raciais abertos.

Para Carvalho (2004) as ações afirmativas são uma resposta ao racismo institucionalizado no Brasil. Tais ações, assim, contribuiriam para oferecer algum nível de igualdade entre os marginalizados e os privilegiados. O que se busca questionar, entretanto, é a medida de efetividade de tais ações para tais populações. Para tanto, é necessário compreender a realidade vivenciada pelos povos marginalizados ao longo das últimas décadas. Pereira (1987) buscou trazer o cenário geral da situação no Brasil, observando as seguintes circunstâncias: o número de brancos empregados no país é extraordinariamente maior do que o número de negros empregados; os negros apresentam uma porcentagem significativamente maior de analfabetismo do que os brancos; os negros também sofrem com maior ocorrência de repetência escolar; é comum o histórico irregular da criança negra, lesado por mais interrupções quando comparado ao histórico escolar de uma criança branca; a incidência de atrás escolar é menor para as crianças brancas, aumentando exponencialmente para as negras de acordo com o amadurecimento; a criança negra e pobre possui 
tratamento diferenciado negativamente e uma menor absorção nas redes de ensino; e, é grande a incidência de professores que consideram o aluno negro ou pobre menos capaz de atingir o sucesso.

A educação e o acesso ao mercado de trabalho são condições que não estão associadas tão somente à possibilidade de sucesso do ser humano civilizado, mas também à sua própria capacidade de sobrevivência. Há uma disparidade, entretanto, que fora observada ao longo de toda a história, inclusive nas últimas décadas, em relação às pessoas brancas e negras. Essa mesma prerrogativa é válida para outros povos, como os povos indígenas, que também enfrentam tais dificuldades. Se, desde a mais tenra idade, a criança negra sofre com o racismo estrutural, institucionalizado e enraizado no país, é natural que a sociedade seja "mais simpática" em relação às ações afirmativas que se traduzem em políticas públicas com o intuito de oferecer um patamar de igualdade para os menos favorecidos, embora exista uma parcela representativa da sociedade que enxergue as ações afirmativas como discriminatórias, no sentido pejorativo.

Schneider (2006) buscou analisar a questão das ações afirmativas como consectárias da busca da eficaz aplicação do princípio constitucional da igualdade, reafirmando a questão do mito da democracia racial como algo que acabou inviabilizando também o entendimento jurídico do problema, compreendendo que o racismo também se faz presente nas práticas sociais e discursos, promovendo a exclusão do indivíduo negro. Ora, as ações afirmativas de fato podem ser consideradas instrumentos que buscam o combate ao racismo, mas as mesmas enquanto políticas públicas são ineficientes para promover mudanças nas práticas sociais e discursos racistas perpetuados no Brasil. $\mathrm{O}$ avanço da sociedade e o aumento do acesso à informação mudaram a forma de pensar da sociedade como um todo, compreendendo que as diferenças raciais não deveriam ser uma questão tão complexa, posto que ela se resume basicamente às diferenças em relação à cor da pele e não há fatores comportamentais oriundos de uma determinada raça.

Ações afirmativas como políticas de cotas, outrossim, ainda que sejam alvo de inúmeras críticas na contemporaneidade, foram idealizadas para cumprir o papel de diminuir as barreiras entre brancos e negros, uma vez que a estrutura do racismo na sociedade acaba negando ao negro uma série de direitos, como o acesso e a permanência no ensino regular em tempo adequado e o acesso ao mercado de trabalho. No entanto, tais ações parecem ser insuficientes para o necessário enfrentamento do problema histórico do racismo no país.

\subsection{Diálogos com a Sociedade Civil}

Segundo Werneck (2016) a discussão em torno das políticas públicas que buscam a diminuição das condições desiguais deve passar diretamente pelo desenvolvimento de mecanismos de diálogo na sociedade civil que garantam a participação de grupos e sujeitos nos processos de formulação, monitoramento e avaliação das políticas e ações. Um diálogo transparente e que assegure a inserção de grupos historicamente marginalizados, como as mulheres negras, permite um maior entendimento sobre a real situação vivenciada por tais grupos perante 0 racismo institucionalizado no país, permitindo o aumento da conscientização da população ao mesmo tempo 
em que fomenta o desenvolvimento de ações afirmativas que possam verdadeiramente produzir uma transformação social em ritmo adequado:

(...) é fundamental que, no lado da sociedade civil, se constituam múltiplos observatórios, articulados entre si, de modo a garantir a replicabilidade e a sustentabilidade das ações ao longo do tempo, permitindo, então, que aprofundem seu alcance de mudança do Estado e suas relações (WERNECK: 2016, p. 548).

Conforme apontado anteriormente, as raízes históricas do racismo acabaram criando um espaço onde, ao mesmo tempo, vidas negras são ocultadas e suas vozes são silenciadas. Ribeiro (2017) defende que é necessário oferecer espaço para que as pessoas que realmente sofrem injustiças sociais possam se manifestar livremente, permitindo um maior acesso à realidade vivenciada por essas pessoas. Monteiro e Simone (2004) apontam que, embora não seja uma tarefa fácil, é essencial a criação de espaços de interlocução entre pesquisadores, militantes e toda a sociedade civil, pois essa imersão contribui para a identificação das vantagens, das dificuldades e do potencial de interação para a produção de conhecimento e para a formulação de políticas públicas/ações afirmativas. Nesse sentido, quando se fala em um diálogo com a sociedade civil em relação ás políticas públicas, é indispensável que haja a participação das pessoas que sofrem com as mazelas do racismo e da discriminação no debate público. Silenciar vozes ou excluir as pessoas negras de uma discussão pública sobre racismo, por exemplo, é mais uma replicação das raízes históricas do racismo brasileiro e do próprio mito da democracia racial, uma vez que tal exclusão pressupõe uma aparente igualdade entre os brancos e os negros, que não se confirma na prática.

Essa mesma visão está presente no estudo de Oliveira Sampaio (2003) aponta que o racismo é um empecilho para a construção de uma democracia propriamente dita, sendo necessárias ações de resgate da cidadania de parcelas da população que tiveram seus direitos e identidades alienados, embasando uma articulação entre a sociedade civil, o Poder Público e as vozes das pessoas discriminadas. Com base nesse entendimento, constata-se que:

Essa insistência em não se perceberem como marcados, em discutir como as identidades foram forjadas no seio de sociedades coloniais, faz com que pessoas brancas, por exemplo, ainda insistam no argumento de que somente elas pensam na coletividade; que pessoas negras, ao reivindicarem suas existências e modos de fazer político e intelectuais, sejam vistas como separatistas ou pensando somente nelas mesmas. Ao persistirem na ideia de que são universais e falam por todos, insistem em falarem pelos outros, quando, na verdade, estão falando de si ao se julgarem universais (RIBEIRO: 2017, p. 20).

De modo algum fala-se em um diálogo com a sociedade civil que contempla apenas os indivíduos negros, por exemplo, assim como não se fala em um diálogo que não contempla os demais atores sociais envolvidos no debate público. É fundamental que a sociedade civil seja pensada sob uma perspectiva inclusiva, na qual todas as pessoas devem ter o direito de exercitar sua livre manifestação e expressão. Contudo, a autora supramencionada defende que a percepção por 
parte da sociedade em relação às reivindicações de militantes e ativistas do movimento negro sejam malvistas: essas pessoas acreditam que as populações negras estão buscando "privilégios", quando, na verdade, a busca se dá por ações afirmativas e políticas públicas como um todo que diminuam o abismo social que separa brancos de negros.

Conforme apontado anteriormente, diversas questões relacionadas à exclusão educacional e à exclusão do mundo do trabalho estão entre os nefastos efeitos do racismo enraizado na sociedade brasileira. Vislumbrar possibilidades para que indivíduos historicamente marginalizados possam ocupar seus espaços no seio educacional e para que sejam reconhecidos como efetivamente capazes e ativos economicamente, assim, contribuiria para o combate contra a exclusão social e para a luta antirracista.

Ainda segundo Ribeiro (2017) a questão relacionada ao debate ao dito "lugar de fala" é bastante ampla, tendo como exemplo o lugar social ocupado pelas mulheres negras, as quais sofrem um preconceito tanto pela ênfase histórica na raça/cor, quanto pela ênfase no gênero feminino. $O$ homem negro, nesse exemplo, enquanto ativista, busca a concretização de ações que consideram tão somente a realidade vivenciada por ele (a questão do racismo), mas pode não se ater à realidade vivenciada pela mulher negra, que sofre ao mesmo tempo com as mazelas do racismo e do machismo em uma sociedade amplamente patriarcal. Autora defende que:

[...] não estamos falando de experiências de indivíduos necessariamente, mas das condições sociais que permitem ou não que esses grupos acessem lugares de cidadania. Seria, principalmente, um debate estrutural. Não se trataria de afirmar as experiências individuais, mas de entender como o lugar social que certos grupos ocupam restringem oportunidades. Ao ter como objetivo a diversidade de experiências, há a consequente quebra de uma visão universal. Uma mulher negra terá experiências distintas de uma mulher branca por conta de sua localização social, vai experenciar gênero de uma outra forma (RIBEIRO: 2017, p. 35).

O diálogo aberto com a sociedade civil, outrossim, abrange um debate estrutural que contempla as questões relacionadas ao gênero, à cor, à classe social, dentre inúmeros outros aspectos. Os indivíduos historicamente marginalizados pelas estruturas de poder herdadas do colonialismo e incentivadas pelo mito da democracia racial passam a reivindicar suas vozes, para que elas possam enriquecer o debate público sobre ações afirmativas e políticas públicas que possam, futuramente, superar tal estrutura. Em suma: ainda que avanços importantes tenham sido realizados ao longo das últimas décadas com o intuito de buscar a superação de problemas como o racismo e outras práticas de discriminação e preconceito, não se pode falar em uma sociedade verdadeiramente comprometida com a transformação sem que ela ofereça o espaço às vozes que precisam ser ouvidas nessa discussão. A mulher negra precisa falar em prol da vivência da mulher negra, assim como o homem negro deve falar em prol da vivência do homem negro e como o indígena deve falar em prol da vivência do indígena, produzindo conhecimentos sobre a realidade desigual do país e estimulando a criação e a discussão em torno de políticas públicas e ações afirmativas que possam ser realmente eficazes. 
O diálogo com a sociedade civil, nesses termos, deve inclusive denunciar constantemente o mito da democracia racial, o qual passou ao longo do tempo uma percepção de uma vivência conjunta e harmoniosa entre diferentes raças no caso brasileiro. Retirar essa maquiagem da história brasileira pode contribuir para fomentar discussões que considerem as prerrogativas históricas do colonialismo e para o exercício do pensamento decolonial, refletindo criticamente sobre os problemas reais enfrentados no país.

\section{INSUFICIÊNCIA DAS MEDIDAS ADOTADAS PELO PODER PÚBLICO}

Neste tópico busca-se analisar, de forma breve e despretensiosa, as medidas que foram efetivadas pelos Poderes Públicos com a finalidade de contribuir para a transformação do atual estado de coisas, estando o presente capítulo dividido em dois subcapítulos: o primeiro que irá discorrer sobre os avanços normativos registrados no Brasil e o segundo que irá expor alguns julgamentos emblemáticos realizados pelo Poder Judiciário.

\subsection{Breve análise das normas vigentes no Brasil buscando promover a proteção dos negros e a igualdade substancial}

O ordenamento jurídico brasileiro conta com diversas normas destinadas ao combate ao racismo, devendo ser mencionado que o país ratificou, em 1968, a Convenção Internacional sobre a eliminação de todas as formas de discriminação racial de 1965, promulgada por meio do Decreto Federal no 65.810/1969 (BRASIL, 1969). No seu artigo 1ำ, referida Convenção consigna que a expressão "discriminação racial" significa qualquer distinção, exclusão, restrição ou preferência baseadas em raça, cor, descendência ou origem nacional ou étnica que tem por objetivo ou efeito anular ou restringir o reconhecimento ou o exercício de direitos humanos e liberdades fundamentais.

Com relação ao direito à educação, a mesma norma internacional prevê em seu artigo V, "e", $v$, que os Estados partes devem se comprometer a proibir e eliminar a discriminação racial em todas as suas formas, promovendo a igualdade ao direito à educação e à formação profissional. Em reforço, o artigo VII estabeleceu que os Estados devem tomar as medidas imediatas e eficazes, especialmente no campo do ensino, da educação, da cultura e da informação, de forma a lutar contra os preconceitos que possam conduzir à discriminação racial.

A Constituição da República Federativa do Brasil de 1988 (CRFB/88) (BRASIL, [1988]), em diversos dos seus dispositivos, busca promover a igualdade e combater todas as formas de racismo. No artigo 1ำ, III, estabelece como fundamento da República Federativa do Brasil a dignidade da pessoa humana; no artigo $3^{\circ}$, IV, consagra como objetivo fundamental da República Federativa do Brasil a promoção do bem de todos, sem preconceitos de origem, raça, cor, idade ou de qualquer forma de discriminação; no artigo $4^{\circ}$, VIII, que trata da atuação do Brasil no âmbito internacional, é destacado o repúdio ao racismo; e o artigo 5ํ, XLI e XLII prevê a prática do racismo como crime inafiançável, imprescritível e com cominação de pena de reclusão (a pena privativa de liberdade mais 
gravosa que pode ser imposta no país). No plano infraconstitucional, a Lei n 7.716/1989 (BRASIL, 1989), trata como crime a discriminação ou preconceito de raça, cor, etnia, religião ou procedência nacional, estabelecendo, por exemplo, em seu artigo 6을 que a recusa, negativa ou impedimento de inscrição ou ingresso de aluno em estabelecimento de ensino público ou privado, de qualquer grau, por preconceito de raça ou cor é crime punível com pena de reclusão de três a cinco anos.

Alguns outros diplomas normativos também visam combater o racismo, nesse sentido: i) a Lei ํo 9.455/1997 (BRASIL, 1997), que define os crimes de tortura, prevê que constitui crime de tortura constranger alguém mediante violência ou grave ameaça, causando-lhe sofrimento físico ou mental, por motivo de discriminação racial (artigo 10 ${ }^{\circ}$ I, "c"); ii) a Lei no 2.889/1956 (BRASIL, 1956), que define e pune o crime de genocídio, estabelece severas sanções para quem atuar com a intenção de destruir, no todo ou em parte, grupo racial (artigo 1ㅜㅗ caput); e iii) a Lei oㅜ 5.250/1967 (BRASIL, 1967), que regula a liberdade de manifestação do pensamento e de informação, define como crime a realização de propaganda com preconceito de raça, com a punição de 1 a 4 anos de detenção (artigo 14); o Código Penal (BRASIL, 1940) preconiza como injúria qualificada a conduta de quem pratica o crime se utilizando de elementos referentes à raça, cor ou origem, com previsão de pena de um a três anos de reclusão (artigo 140, § 3o); o Estatuto de Roma do Tribunal Penal Internacional, do qual o Brasil é signatário (BRASIL, 2002), estabelece no seu artigo 6ำ que configura genocídio os atos praticados com a intenção de destruir, no todo ou em parte, grupo racial.

No plano das medidas afirmativas, destaca-se a Lei no 12.990/2014 (BRASIL, 2014), que determinou a reserva aos candidato negros de $20 \%$ das vagas oferecidas nos concursos públicos para provimento de cargos efetivos e empregos públicos, no âmbito da Administração Pública Federal direta e indireta, existindo ainda diversas outras legislações estaduais e municipais no mesmo sentido, a exemplo dos Estados do Paraná (PARANÁ, 2003), Mato Grosso do Sul (MATO GROSSO DO SUL, 2008) São Paulo (SÃO PAULO, 2015) e dos municípios de São Paulo (SÃO PAULO, 2013) e de Porto Alegre (PORTO ALEGRE, 2014).

No âmbito do Poder Judiciário e do Ministério Público, o Conselho Nacional de Justiça (CNJ) elaborou a Resolução no 203/2015 (BRASIL, 2015) e o Conselho Nacional do Ministério Público (CNMP) a Resolução no 170/2017 (BRASIL, 2017a), ambas reservando ao menos 20\% das vagas para candidatos negros nos concursos públicos para ingresso nas carreiras do Poder Judiciário e do Ministério Público no país.

Da forma semelhante, várias Universidades Públicas utilizam o critério das cotas raciais para a seleção de estudantes, a exemplo da Universidade de Brasília (UnB) que foi a primeira a adotar esse tipo de medida, por meio do seu Plano de Metas para a Integração Social, Étnica e Racial, aprovado em 06 de junho de 2003, que estabeleceu que $20 \%$ das vagas do vestibular deveriam ser destinadas a candidatos negros, tendo a medida entrado em vigor no ano seguinte. Registra-se ainda a importante Lei 10.639/2003 (BRASIL, 2003), que modifica a Lei no 9.394/1996 e estabelece as diretrizes e bases da educação nacional, que será abordada no capítulo 6 deste trabalho.

Diante do exposto, observa-se que, em que pese terem sido adotadas medidas importantes no plano normativo, como as políticas afirmativas de cotas raciais em concursos públicos e universidade públicas, a farta legislação internacional e nacional sobre o problema da desigualdade 
racial, inclusive no âmbito criminal, não foi suficiente para erradicar o racismo ou mitigar os seus efeitos perniciosos no Brasil, especialmente no que se refere à desigualdade social.

\subsection{Análise de importantes decisões judiciais proferidas sobre o assunto}

Conforme destacado neste estudo, o problema da discriminação racial é antigo e ultrapassa as fronteiras brasileiras. Nessa perspectiva, Lenza (2020) destaca-se o separate but equal que vigorou por muito tempo nos Estados Unidos, consistindo na separação de brancos e negros, assegurando, porém, uma prestação de serviços idêntica, com a mesma qualidade. Desta forma, existiam, por exemplo, escolas para brancos e para negros, mas apesar de separados, a qualidade do ensino deveria ser a mesma, acontecendo o mesmo com relação ao transporte, com vagões separados para brancos e negros (LENZA, 2020).

Esse entendimento, inclusive, foi estabelecido pela Suprema Corte dos Estado Unidos no precedente Plessy v. Ferguson, 163 U.S. 537, de 18.05.1896, permanecendo vigente por décadas, com o entendimento de que a segregação não violava a $14^{\mathrm{a}}$ emenda, que estabelece a cláusula de proteção de iguais (LENZA, 2020). Apenas em 1954, no caso Brown v. Board of Education, 347 U.S. 483, 1954, esse posicionamento foi revisto pela Suprema Corte Americana, por 9 votos a 0 , representando um verdadeiro marco no movimento de direitos civis, com a declaração da inconstitucionalidade da segregação racial entre estudantes brancos e negros nas escolas públicas do país, com fundamento na violação da mesma cláusula de proteção de iguais, prevista na $14^{\text {a }}$ emenda, que recebeu uma nova interpretação (LENZA, 2020).

No Brasil, o Supremo Tribunal Federal (STF) proferiu julgamento sobre a política de cotas raciais, na Arguição de Descumprimento de Preceito Fundamental (APPF) no 186 (BRASIL, 2012), considerando constitucional a política de cosas étnico-raciais para seleção de estudantes pela UnB. O relator da ação, Ministro Ricardo Lewandowski apontou que as cotas tinham o propósito de correção das desigualdades sociais historicamente determinadas e a promoção da diversidade cultural na comunidade acadêmica e científica, constituindo medida adequada e proporcional para atingir os fins pretendidos pela política pública estabelecida pela Unb. Da mesma forma, o STF, no julgamento da Ação Declaratória de Constitucionalidade (ADC) № 41 (BRASIL, 2017b), reconheceu a validade da Lei Federal ํo 12.990/2014, mencionada no tópico anterior, que estabeleceu a reserva de vagas aos negros nos concursos públicos no âmbito da Administração Pública Federal.

Conforme se observa, o Poder Judiciário, ao longo da sua história, sempre acompanhou o contexto social de cada período, tendo a Suprema Corte dos Estados Unidos, um dos países mais desenvolvidos do mundo, chancelado a segregação racial por décadas.

Nos últimos anos foram proferidas importantes decisões judiciais que confirmaram a constitucionalidade e a necessidade/adequação da adoção de políticas públicas para a redução das desigualdades sociais, mas o grave problema do racismo carece, conforme se observa neste estudo, de outras formas mais efetivas de enfrentamento. 


\section{RACISMO E SOCIEDADE: TRANSFORMAÇÃO SOCIAL A PARTIR DA EDUCAÇÃO E DA ECONOMIA}

Como visto, ao longo da história brasileira foi possível observar mais tentativas de mascarar os problemas envolvendo racismo e desigualdades na sociedade, como no caso do mito da democracia racial, que retratava uma realidade harmônica entre negros, indígenas e brancos que nunca foi concretizada até então. Ficou evidenciado no presente estudo que, para que possa haver uma real transformação social, as discussões acerca do racismo estrutural no Brasil devem ser concebidas a partir de uma perspectiva decolonial, que compreende os impactos das práticas oriundas do colonialismo e perpetuadas ao longo da história. Tal debate com a sociedade civil deve permitir um diálogo onde as vozes dos marginalizados e excluídos sejam encorajadas. Mas, cumprese indagar, como é possível falar em transformação social ao conceber as variáveis indissociáveis do racismo e da estrutura social? Foi verificado ao longo dos últimos capítulos que o racismo estruturado no Brasil é um agente promotor da exclusão social das pessoas negras e de outros grupos marginalizados como os indígenas, provocando uma série de fenômenos, como a maior evasão escolar e maior índice de analfabetismo entre os marginalizados, além de dificuldades consistentes de tais grupos em relação ao acesso ao mercado de trabalho se comparados aos níveis de empregabilidade das pessoas brancas.

Assim, serão contempladas as perspectivas educacionais e econômicas que abrangem a possibilidade de transformação social. De modo algum são negadas as importantes transformações sociais ocorridas ao longo das últimas décadas em uma tentativa de amenizar os impactos das raízes e ecos históricos do racismo, mas sim enfatizar que é necessário fazer mais para que seja realmente possível promover mudanças reais na estrutura social que diminuam as barreiras entre brancos e negros, ilustrando também a questão de outros povos marginalizados. Ora, ao considerar as transformações sociais e legais que ocorreram recentemente, é possível apontar para um caminho que busca a diminuição das dificuldades provocadas pelo racismo. Mas, se considerarmos que existe uma harmonia plena e plenas condições de igualdade entre brancos e negros, corremos o risco de incidir no mesmo "erro" ou "má ação" envolvendo o mito da democracia racial: o combate ao racismo, mesmo constante, ainda não produziu resultados suficientes.

Segundo Ribeiro e Melo (2019) o pensamento decolonial da América Latina versa sobre uma educação voltada para a democratização das relações sociais e para a formação de cidadãos críticos e reflexivos, com uma proposta freireana voltada para o diálogo em busca de uma proposta decolonial que supera o pensamento do aluno passivo e dá origem ao sujeito transformador, que possui voz e existência reconhecidas no campo sócio educacional. De acordo com os autores, a contribuição de Freire para o decolonialismo passa a ideia de uma educação estruturada a partir do diálogo de saberes, de convivências epistemológicas e ontológicas, com um currículo aberto para os saberes não eurocêntricos, permitindo que todos se tornem sujeitos do conhecimento.

Oliveira e Candau (2010, p. 37) afirmam que "além de uma luta decolonial de poder e de saber, para os afrodescendentes a colonialidade do ser é fator relevante nas disputas epistêmicas no campo educacional". O campo educacional não deve refletir uma situação do negro como um refém 
do sonho de "embranquecimento", permitindo que o negro manifeste sua identidade para muito além do mito da democracia racial, se engajando na luta pela transformação social. Assegurar ao indivíduo negro o acesso e à permanência na escola dentro do tempo normal é uma verdadeira possibilidade para a transformação social, pois é a educação que liberta e que faz com que o indivíduo seja apto para o exercício de sua cidadania, conscientizando-se politicamente e desenvolvendo-se intelectualmente. Em contrapartida, a perpetuação da exclusão escolar das populações negras eco as influências coloniais da história brasileira, passando uma falsa noção de que a educação e as atividades intelectuais estão reservadas apenas para a população branca.

De acordo com Mesquita (2019) a indispensável necessidade de promover a inclusão escolar das crianças negras não é suficiente para se falar em uma verdadeira transformação social, uma vez que boa parte da população negra já enfrentou a problemática do racismo estrutural, sendo impedidos de frequentar a escola no tempo ideal e contando com índices de evasão escolar. Por isso, é necessário vislumbrar também a Educação de Jovens e Adultos (EJA) como uma modalidade que promove a transformação social, uma vez que ela permite ao jovem e ao adulto negro que o mesmo exerça o seu direito à educação e o seu exercício à cidadania, inclusive concebendo processos de alfabetização. É fundamental que todas as gerações sejam concebidas no contexto educacional para que todos os indivíduos possam se desenvolver intelectualmente e promover uma verdadeira transformação social.

Fernandes (1978) contempla que o racismo estrutural buscou assegurar que o negro estaria em um nível de educação inferior em relação ao homem branco, dificultando que o negro pudesse assim obter promoções não tão somente no contexto das atividades civis, mas também nas atividades dentro das Forças Armadas. Ora, quando o negro tem renegado o seu direito à educação, ele acaba tendo uma série de prejuízos, como as dificuldades de ingresso e permanência no mercado de trabalho e, quando o mesmo está inserido, ele acaba contando com dificuldades de promoção e crescimento profissional tanto pela sua educação de nível inferior quanto pelo próprio tom de sua pele. Outro ponto importante ainda em matéria educacional se refere aos conteúdos ministrados. A Lei 10.639/2003 determina que:

Art. 26-A. Nos estabelecimentos de ensino fundamental e médio, oficiais e particulares, torna-se obrigatório o ensino sobre História e Cultura AfroBrasileira. § 1ㅇ $\mathrm{O}$ conteúdo programático a que se refere o caput deste artigo incluirá o estudo da História da África e dos Africanos, a luta dos negros no Brasil, a cultura negra brasileira e o negro na formação da sociedade nacional, resgatando a contribuição do povo negro nas áreas social, econômica e política pertinentes à História do Brasil. § 20 Os conteúdos referentes à História e Cultura Afro-Brasileira serão ministrados no âmbito de todo o currículo escolar, em especial nas áreas de Educação Artística e de Literatura e História Brasileiras (BRASIL: 2003, s/n).

É fundamental o reconhecimento de uma história brasileira que não seja estabelecida pelo mito da democracia racial ou pela ideia da inexistência do racismo. Reconhecer o espaço dos indivíduos negros, a história dos povos e da escravidão e outros aspectos relacionados à estruturação da sociedade brasileira é requisito básico para uma educação que de fato possa ser 
transformadora em função destes indivíduos, dando espaço para o pensamento decolonial e para a ruptura de ideias relacionadas ao racismo enraizado no país. Segundo Clockl et al. (2018) o papel desempenhado pelo professor na contemporaneidade não envolve a inclusão de novas tarefas ao docente, mas sim a consideração das demandas presentes nas salas de aula e nos espaços de atuação e de transformação da sociedade. Assim, tanto os professores quanto as instituições de ensino e demais atores envolvidos nos processos educacionais devem fomentar uma educação que seja ao menos tempo inclusiva e transformadora, alheia aos preceitos fomentados pelo mito da democracia racial e mais alinhada ao movimento decolonial.

Uma educação transformadora, outrossim, deve escancarar o problema do racismo estrutural enraizado na história brasileira para que de fato ela possa produzir transformações sociais, fazendo com que o aluno negro compreenda a existência de sua identidade e possa produzir as modificações que deseja ver no mundo, posto que é a educação que confere mais autonomia e independência ao indivíduo, aspectos fundamentais para o exercício da cidadania. O indivíduo negro, bem como qualquer outro indivíduo pertencente a grupos marginalizados, como os indígenas, passa a reivindicar sua voz para a reflexão sobre os problemas estruturais da sociedade e os caminhos para o seu enfrentamento. Outra questão fundamental que envolve a transformação social nessa perspectiva é o ponto econômico. Fernandes (1978) ressalta que o papel do indivíduo negro na economia sempre fora resumi do à força de trabalho, com os africanos escravizados contemplados como meros objetos que sequer eram considerados como seres humanos. Contudo, a evolução social e econômica do Brasil, mesmo com a abolição da escravidão e com a criação de políticas públicas e ações afirmativas que buscavam amenizar os efeitos insólitos do racismo estrutural do Brasil, não surtiu os efeitos necessários para que o indivíduo marginalizado de fato pudesse ser concebido como um ser dotado de capacidade econômica (em condições de igualdade), uma vez que, como visto anteriormente, há maior proporção de negros do que de brancos fora do mercado de trabalho.

Batista e Mastrodi (2018) apontam que, naquele sistema, uma vez que "o trabalho era desenvolvido a partir de mão-de-obra escrava, impunha-se justificar a objetificação dos negros e o uso da violência física para a manutenção da ordem econômica", sendo a sociedade escravagista estruturada a partir da desigualdade fundamental entre negros e brancos para que o sistema funcionasse. Os autores versam sobre fundamentos extra econômicos do racismo no Brasil ao longo da história, com o sistema social racista que negociava a força de trabalho negra para fins econômicos. No entanto, se analisarmos tal questão sob a perspectiva racional e de eficiência econômica proposta no estudo, não haveria motivos para a permanência e perpetuação do racismo com o fim do sistema escravagista e na consolidação do modo de produção capitalista, o que não se confirmou na prática.

De acordo com os autores supramencionados, o racismo não é uma questão que deve ser analisada sob um prisma exclusivamente econômico, uma vez que sua manifestação atinge as pessoas negras, independentemente de sua classe social. E, para os fins pretendidos para o desenvolvimento do presente estudo, não se busca vislumbrar o racismo como uma prática exclusivamente consolidada no âmbito financeiro e econômico (uma vez que, se esse fosse o caso, 
apenas homens e mulheres negros das classes sociais seriam atingidos pelo racismo), mas sim contemplar a economia como uma possibilidade de transformação social ao lado da educação.

A questão do racismo estrutural no Brasil deve ser concebida em uma perspectiva que envolve tanto a economia quanto a sociedade como um todo, refletindo sobre pontos como o acesso ao mercado de trabalho (CHADAREVIAN: 2009). Para Santos (2019) alguns pontos são fundamentais para enfrentar o que o autor denomina como racismo organizacional, que impede e dificulta o acesso e a permanência do indivíduo negro no mercado de trabalho, como o combate às práticas discriminatórias no âmbito da seleção e recrutamento de pessoas com ações efetivas, realização de pesquisas para identificar práticas racistas na organização e o trabalho com a necessidade de implementação e reconhecimento dos direitos humano como uma base de conscientização social e garantia dos cumprimentos regidos por força de lei:

Tais práticas discriminatórias foram avaliadas ou discutidas por meio das diferenças salariais e dificuldades para os negros ocuparem cargos com maior status social dentro de uma organização (...) foi possível identificar que, ainda há diferenciação e favorecimento a indivíduos não negros, constituindo, um paradigma social ainda distante de ser quebrado e adotar um novo modelo a ser seguido. Se hoje o mundo está impregnado com essas práticas discriminatórias que se arrastam ao longo do tempo, cabe às organizações buscarem alternativas que combatam tais práticas tão arcaicas que assolam a nossa história (SANTOS: 2019, p. 29).

O racismo enraizado, nesses termos, está presente também nas organizações. O negro possui uma grande desigualdade de oportunidades em relação ao indivíduo branco, o que se reflete não apenas no acesso ao mercado de trabalho, como também nas circunstâncias sob as quais os mesmos atuam profissionalmente, obtendo mais dificuldades de ascensão profissional e de ocupação de cargos com status e salários mais elevados.

Embora o enfrentamento do racismo no âmbito do mercado de trabalho seja um aspecto fundamental para que se possa falar em uma transformação social propriamente dita, a discussão é ainda mais profunda. Campos (2018) realizou um estudo sobre a valorização da pessoa negra no Brasil e o afroempreendedorismo (ou empreendedorismo negro), apontando que a atividade empreendedora pode consistir em uma proposta emancipatória e transformadora para a realidade do negro no país:

A realização profissional é um dos principais achados neste estudo. A realização profissional do negro e negra no Brasil mostra um reflexo de um lugar em que a população negra está começando a se inserir. Trabalhar no seu empreendimento é algo extremamente significativo para este grupo considerando a sua trajetória histórica no país, uma trajetória de resistência e lutas para conseguir alcançar a todos os espaços que estão sendo conquistados. O afroempreendedor apresenta um rompimento com as lógicas racistas impostas que permeiam desde a época da escravidão. E é possível identificar esse aspecto ao observar as inúmeras repetições em relação a capacidade dos afroempreendedores de fazer e de ocupar todos os espaços (CAMPOS: 2018, p. 25). 
O empreendedorismo negro, assim, vem ganhando destaque no enfrentamento das práticas racistas relacionadas às atividades empreendedoras. Quando o negro atua como empreendedor, ele rompe com um paradigma histórico de que aquele não é o seu lugar ou de que apenas homens brancos deveriam fundar e desenvolver empresas. Quando se fala em transformação social, se fala na verdade em uma igualdade que, embora ainda distante, se faz plenamente possível ao estabelecer diálogos, estabelecer o pensamento decolonial e contar sobretudo com os esforços dos próprios indivíduos negros em transformar suas vivências, mesmo em um contexto desfavorável e abertamente racista. Isso posto, é possível afirmar que a transformação social é um processo que passar diretamente por aspectos relacionado à economia e à educação, reafirmando que a democracia racial ainda é apenas um mito e denunciando a necessidade de estabelecer o pensamento decolonial. $\mathrm{O}$ racismo persiste como uma realidade no Brasil e em uma quantidade expressiva de países até os dias de hoje, em uma perspectiva que determina que aponta que, embora tenhamos deixado o primitivo, ainda não alcançamos o sofisticado, reafirmando uma luta constante para a produção de uma real igualdade.

\section{CONSIDERAÇÕES FINAIS}

Desde a colonização das terras tupiniquins, o racismo passou a ser uma prática institucionalizada e enraizada no caso brasileiro. Teorias como o mito da democracia racial, nesses termos, acabam prestando um enorme desserviço ao relatarem uma inexistente igualdade entre pessoas brancas e não-brancas, como negros e indígenas, posto que as desigualdades sempre existiram e são bastante profundas na sociedade brasileira até nos tempos atuais, mesmo com a realização de importantes avanços nesse sentido ao longo das últimas décadas.

Para a desconstrução do mito da democracia racial, o presente estudo se embasou no pensamento decolonial como uma prática social de descolonização da educação e da sociedade como um todo, a tornando mais humanizadora com a promoção da conscientização de sujeitos que foram silenciados e marginalizados pelo eurocentrismo e pela colonização e da emancipação de saberes e identidades. No mesmo sentido, a marginalização dos povos foi retratada como multifacetária: uma mulher negra, por exemplo, sofre não apenas com o racismo estrutural, mas também com o machismo de uma sociedade brasileira patriarcal; já o homem negro, sente na pele apenas as mazelas do racismo, sem sofrer preconceito em relação ao gênero; e, no mesmo sentido, as práticas sociais de discriminação e preconceitos são distintas, por exemplo, entre as populações negras e indígenas, mesmo com ambas sendo marginalizadas. Em que pese o fato da democracia racial ser um mito já derrubado e que nunca refletiu a realidade da sociedade brasileira, avanços importantes foram realizados nas últimas décadas com o intuito de promover algum grau de igualdade entre povos brancos e não-brancos que constituem a sociedade brasileira, embora tais avanços sejam considerados ainda insuficientes ao comparar a situação de pessoas brancas e negras, por exemplo, na contemporaneidade: o acesso e a permanência na escola e no mercado de trabalho são significativamente mais baixos para as pessoas negras, ao mesmo passo em que índices de analfabetismo e de evasão escolar são consideravelmente mais altos. 
Considerando a insólita herança histórica do racismo que se reflete até hoje na realidade brasileira, a educação e a economia foram contempladas como perspectivas voltadas para a transformação social: somente quando houver a plena inclusão dos marginalizados no âmbito educacional e econômico, será possível efetivar o combate ao racismo, fazendo com que tais grupos possam se tornar mais autônomos e independentes, plenamente aptos para o exercício da cidadania e para engajar uma luta política e social contra o racismo estrutural no país.

\section{REFERÊNCIAS}

ALMEIDA, S. O que é racismo estrutural? Belo Horizonte: Letramento, 2018.

ANDREWS, G.R. Democracia racial brasileira 1900-1990: um contraponto americano. Estudos Avançados 11 (30), 1997.

BALLESTRIN, L. América Latina e o giro decolonial. Revista Brasileira de Ciência Política, ㄲo11. Brasília, maio - agosto de 2013, pp. 89-117.

BARBOSA LIMA, S.T. Direitos Humanos dos Negros: Racismo estrutural, necropolítica, interseccionalidade e o mito da democracia racial no Brasil. REH-REVISTA EDUCAÇÃO E HUMANIDADES, Volume I, número 2, jul-dez, 2020, pág.119-132.

BATISTA, W.M; MASTRODI, J. Dos fundamentos extraeconômicos do racismo no Brasil. Rev. Direito Práx., Rio de Janeiro, vol. 9, n. 4, 2018, p. 2332-2359.

BOUTELDJA, H. Raça, Classe E Gênero: Uma Nova Divindade De Três Cabeças. Cadernos de Gênero e Diversidade, Vol 02, N. 02 - Jul. - Dez., 2016.

BRASIL. Constituição da República Federativa do Brasil, de 5 de outubro de 1988. Brasília:

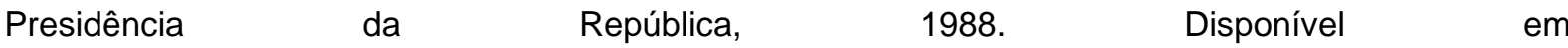
<http://www.planalto.gov.br/ccivil_03/constituicao/constituicao.htm> Acesso: ago. 2020.

BRASIL. Decreto 4.388, de 25 de setembro de 2002. Brasília: Presidência da República, 2002. Disponível em < http://www.planalto.gov.br/ccivil_03/decreto/2002/d4388.htm> Acesso: ago. 2020.

BRASIL. Decreto 65.810, de 8 de dezembro de 1969. Brasília: Presidência da República, 1969. Disponível em <http://www.planalto.gov.br/ccivil_03/decreto/1950-1969/D65810.html> Acesso: ago. 2020. 
BRASIL. Decreto-Lei 2.848, de 31 de dezembro de 1940. Brasília: Presidência da República, 1940. Disponível em <http://www.planalto.gov.br/ccivil_03/decreto/1950-1969/D65810.html> Acesso: ago. 2020.

BRASIL. Lei 2.889, de 1ํ de outubro de 1956. Brasília: Presidência da República, 1956. Disponível em < http://www.planalto.gov.br/ccivil_03/leis/l2889.htm> Acesso: ago. 2020.

BRASIL. Lei 5.250, de 9 de fevereiro de 1967. Brasília: Presidência da República, 1967. Disponível em

<http://www.planalto.gov.br/ccivil_03/leis/15250.htm\#: :text=Regula\%20a\%20liberdade\%20de\%20ma nifesta\%C3\%A7\%C3\%A30\%20do\%20pensamento\%20e\%20de\%20informa\%C3\%A7\%C3\%A3o.\&tex $\mathrm{t}=$ Art\%20.,lei\%2C\%20pelos\%20abusos\%20que\%20cometer> Acesso: ago. 2020.

BRASIL. Lei 7.716, de 5 de janeiro de 1989. Brasília: Presidência da República, 1989. Disponível em <http://www.planalto.gov.br/ccivil_03/leis/17716.htm> Acesso: ago. 2020.

BRASIL. Lei 9.455, de 7 de abril de 1997. Brasília: Presidência da República, 1997. Disponível em < http://www.planalto.gov.br/ccivil_03/leis/L9455.htm> Acesso: ago. 2020.

BRASIL. Lei 10.639, de 9 de janeiro de 2003. Brasília: Senado Federal, 2003. Disponível em <http://www.planalto.gov.br/ccivil_03/leis/2003/110.639.htm> Acesso: ago. 2020.

BRASIL. Lei 12.990, de 9 de junho de 2014. Brasília: Presidência da República, 2014. Disponível em < http://www.planalto.gov.br/ccivil_03/_ato2011-2014/2014/lei/112990.htm> Acesso: ago. 2020.

BRASIL. Resolução 170, de 13 de junho de 2017. Brasília: Conselho Nacional do Ministério Público, 2017a. Disponível em $<$ https://www.cnmp.mp.br/portal/images/Resolucoes/Resolu\%C3\%A7\%C3\%A3o-170.pdf> Acesso: ago. 2020.

BRASIL. Resolução 203, de 23 de junho de 2015. Brasília: Conselho Nacional de Justiça, 2015. Disponível em < https://atos.cnj.jus.br/atos/detalhar/2203> Acesso: ago. 2020.

BRASIL. Supremo Tribunal Federal. Acórdão na ADC 41/DF. Relator: Min. Roberto Barroso, j. 08.06.2017b.

BRASIL. Supremo Tribunal Federal. Acórdão na ADPF 186/DF. Relator: Min. Ricardo Lewandowski, j. 26.04.2012. 
CAMPOS, A.A. A Valorização do negro no Brasil e o afroempreendedorismo. Monografia (Graduação em Administração) - Universidade Federal de Outro Preto, Mariana, 2018.

CARVALHO, J.J. As Ações Afirmativas Como Resposta Ao Racismo Acadêmico E Seu Impacto Nas Ciências Sociais Brasileiras. Série Antropologia, 358, Brasília, 2004.

CHADAREVIAN, P.C. Existe uma Teoria Econômica da Discriminação? Tese (Pós-graduação em Economia Aplicada) - Universidade Federal de São Carlos, Sorocaba, 2009.

CLOCK, L. M et al. Profissão docente no século XXI: concepções do professor sobre seu papel na sociedade contemporânea. Conjectura: Filos. Educ., Caxias do Sul, v. 23, n. 1, p. 77-96, jan./abr. 2018.

COLAÇO, T.L; DAMÁZIO, E.S.P. Novas Perspectivas para a Antropologia Jurídica na América Latina: o Direito e o Pensamento Decolonial. Florianópolis: Fundação Boiteux, 2012.

FERNANDES, F. O Genocídio do Negro Brasileiro: Processo de um Racismo Mascarado. Rio de Janeiro: Paz e Terra, 1978.

GUIMARÃES, A.S.A. A Democracia Racial Revisitada. Rev. Afro-Ásia, 60, 9-44, 2019.

HOFBAUER, A. Ações afirmativas e o debate sobre racismo no Brasil. Lua Nova, São Paulo, 68: 9$56,2006$.

LENZA, Pedro. Direito Constitucional Esquematizado. 24. ed. São Paulo: Saraiva Educação, 2020. EBook.

MATO GROSSO DO SUL. Lei 3.594, de 10 de dezembro de 2008. Mato Grosso do Sul: Assembleia Legislativa, $2008 . \quad$ Disponível em < http://aacpdappls.net.ms.gov.br/appls/legislacao/secoge/govato.nsf/1b758e65922af3e904256b220050 342a/fe9c2343a02429470425751c0047504e?OpenDocument\&Highlight=2,3.594> Acesso: ago. 2020.

MESQUITA, T. V. L. Exclusão Escolar Racializada: Implicações do racismo na trajetória de educandos da EJA. 1 ed. Jundiaí: Paco Editorial, 2019.

MONTEIRO, S; SANSONE, L (orgs.) Etnicidade na América Latina: um debate sobre raça, saúde e direitos reprodutivos Rio de Janeiro: Fiocruz. 2004. 
NASCIMENTO, M.M; PIRRA, R.R.R. Educação decolonial e formação intelectual no Brasil. Anais Eletrônicos do Congresso Epistemologias do Sul v. 2, n. 1, 2018. Disponível em <https://revistas.unila.edu.br/aeces/article/view/728> Acesso: jul. 2020.

NOVAIS REIS, M; ANDRADE, M.F.F. O pensamento decolonial: análise, desafios e perspectivas. Revista Espaço Acadêmico, 17(202), 2018, p. 01-11.

OLIVEIRA SAMPAIO, E. Racismo Institucional: desenvolvimento social e políticas públicas de caráter afirmativo no Brasil. INTERAÇÕES - Revista Internacional de Desenvolvimento Local. Vol. 4, N. 6, p. 77-83, mar. 2003.

OLIVEIRA, L.F; CANDAU, V.M.F. Pedagogia decolonial e educação antirracista e intercultural no Brasil. Educ. rev. [online]. 2010, vol.26, n.1, pp.15-40. Disponível em <http://www.scielo.br/pdf/edur/v26n1/02.pdf> Acesso: jul. 2020.

PARANÁ. Lei 14.274, de 24 de dezembro de 2003. Paraná: Assembleia Legislativa, 2003. Disponível em < https://leisestaduais.com.br/pr/lei-ordinaria-n-14274-2003-parana-reserva-vagas-a-afrodescendentes-em-concursos-publicos-conforme-especifica> Acesso: ago. 2020.

PEREIRA, J. B.B. A criança negra: identidade étnica e socialização. Cadernos de Pesquisa, São Paulo, ํㅡㄴ 63, 1987.

PONTES E SILVA, D.B.P; FLORENCIO, S.P.N. Racismo, infância e escola: reflexões sobre a temática racial na Educação Infantil. Revista Com Censo\#13 • volume 5 • número 2 • maio 2018.

PORTO ALEGRE. Lei Complementar 746/2014, de 03 de novembro de 2014. Porto Alegre: Prefeitura Municipal, 2014.2 Disponível em < http://www2.portoalegre.rs.gov.br/gpn/default.php?p_secao=139\#: :text=Complementar\%20746\%2F2 014-,Art.,do\%20Munic\%C3\%ADpio\%20de\%20Porto\%20Alegre.> Acesso: ago. 2020.

PRODANOV, C. C.; FREITAS, E. C. Metodologia do trabalho científico [recurso eletrônico]: métodos e técnicas da pesquisa e do trabalho acadêmico. 2. ed. Novo Hamburgo: Feevale, 2013.

QUADROS, M.F. Descolonizando As Relações Internacionais: a raça e o racismo como categoria de análise. Semina - Revista dos Pós-Graduandos em História da UPF, V. 18, N. 1, p. 39 - 57, JAN/JUL 2019.

RIBEIRO, D. Quem tem medo do feminismo negro? São Paulo: Companhia das Letras, 2018. 
RIBEIRO, D; MELO, A. Reflexões decoloniais sobre conhecimento e educação a partir do diálogo em Paulo Freire. Diálogos Latinoamericanos 28 (2019). Disponível em < https://tidsskrift.dk/dialogos/article/view/115941/166027> Acesso: Jan. 2020.

RIBEIRO, D. O que é lugar de fala?. Belo Horizonte: Letramento, 2017.

SANTOS, M. O Negro no mercado de trabalho: o preconceito nas organizações. Trabalho de Conclusão de Curso (Graduação em Administração) - Faculdade CESMAC do Sertão, Palmeira dos Índios, 2019.

SÃO PAULO. Lei 15.939, de 23 de dezembro de 2013. São Paulo: Câmara Municipal, 2013. Disponível em < https://leismunicipais.com.br/a/sp/s/sao-paulo/lei-ordinaria/2013/1593/15939/leiordinaria-n-15939-2013-dispoe-sobre-o-estabelecimento-de-cotas-raciais-para-o-ingresso-de-negrose-negras-no-servico-publico-municipal-em-cargos-efetivos-e-comissionados> Acesso: ago. 2020.

SÃO PAULO. Lei Complementar 1.259, de 15 de janeiro de 2015. São Paulo: Assembleia Legislativa, 2015.

Disponível

em

<https://www.al.sp.gov.br/repositorio/legislacao/lei.complementar/2015/lei.complementar-125915.01.2015.html> Acesso: ago. 2020.

SCHNEIDER, Y. A (In) Efetividade dos Direitos Fundamentais no Estado Democrático de Direito; As Ações Afirmativas como consectárias da busca da eficaz aplicação do princípio constitucional da igualdade. Dissertação (Pós-Graduação em Direito) - Universidade do Vale do Rio dos Sinos, São Leopoldo, 2006.

SILVA, M.L; SKOLAUDE, M.S. 1ํㅡㄹ Congresso Afro-Brasileiro (1934), biopolítica e democracia racial: implicações na educação contemporânea. Revista Brasileira de História \& Ciências Sociais (RBHCS) - vol. 12, n. 23, jan./jun. 2020.

UnBNOTÍCIAS (Brasília). Repórter. Aprovação das cotas raciais na UnB completa 15 anos. 2018. Elaborada por Serena Veloso. Disponível em <https://www.noticias.unb.br/76-institucional/2319aprovacao-das-cotas-raciais-na-unb-completa-15-anos> Acesso: ago. 2020.

VIDAL, L.S. É possível haver democracia no Brasil sem real democracia racial? (Internet). Seção Roda, 2020. Disponível em < https://publicacoes.degase.rj.gov.br/index.php/revistaau/article/view/epossivel-haver-democracia-no-brasil-sem-real-democracia-racial/132 > Acesso: jul. 2020.

WERNECK, J. Racismo institucional e saúde da população negra. Saúde Soc. São Paulo, v.25, n.3, p.535-549, 2016.

Revista do Direito [ISSN 1982-9957]. Santa Cruz do Sul, n. 63, p. 79-104, jan. 2021. https://online.unisc.br/seer/index.php/direito/index 
WESTRUP, C; BARABAS, T.B. Racismo E A Perspectiva Decolonial: Analise Das Teorias Raciais No Brasil A Partir Do Século XIX. Direitos Humanos, Estado Democrático de Direito e Direitos Sociais, UNESC-Criciúma, set. 2019.

Disponível

em <http://periodicos.unesc.net/AnaisDirH/article/view/5787/5201> Acesso: ago. 2020. 